\title{
Erratum to: NLK functions to maintain proliferation and stemness of NSCLC and is a target of metformin
}

Dong Suwei ${ }^{1,2}$, Zeng Liang ${ }^{3}$, Liu Zhimin², Li Ruilei ${ }^{2}$, Zou Yingying ${ }^{4}$, Li Zhen ${ }^{1,2}$, Ge Chunlei ${ }^{2}$, Lai Zhangchao ${ }^{2}$, Xue Yuanbo ${ }^{2}$, Yang Jinyan ${ }^{2}$, Li Gaofeng ${ }^{5}$ and Song Xin ${ }^{1,2^{*}}$

\section{Erratum}

Following the publication of this article [1], the authors noticed that the text contained an error. Within the text 'TLF4' should be 'KLF4'.

\begin{abstract}
Author details
${ }^{1}$ Cancer Research Institute of Southern Medical University, Guangzhou, Guangdong, People's Republic of China. ${ }^{2}$ Department of Cancer Biotherapy Center, The Third Affiliated Hospital of Kunming Medical University (Tumor Hospital of Yunnan Province), Kunming, Yunnan, People's Republic of China. ${ }^{3}$ Department of Pathology, Hunan Tumor Hospital, Changsha, Hunan, People's Republic of China. ${ }^{4}$ Department of Pathology and Pathophysiology, Kunming Medical University, Kunming, Yunnan, People's Republic of China. ${ }^{5}$ Department of Thoracic Surgery, The Third Affiliated Hospital of Kunming Medical University (Tumor Hospital of Yunnan Province), Kunming, Yunnan, People's Republic of China.
\end{abstract}

Published online: 17 February 2016

\section{Reference}

1. Song $X$ et al. NLK functions to maintain proliferation and stemness of NSCLC and is a target of metformin. J Hematol Oncol. 2015;8:120.

\footnotetext{
*Correspondence: songxin68@126.com

${ }^{1}$ Cancer Research Institute of Southern Medical University, Guangzhou, Guangdong, People's Republic of China

${ }^{2}$ Department of Cancer Biotherapy Center, The Third Affiliated Hospital of Kunming Medical University (Tumor Hospital of Yunnan Province), Kunming, Yunnan, People's Republic of China
}

Submit your next manuscript to BioMed Central and we will help you at every step:

- We accept pre-submission inquiries

- Our selector tool helps you to find the most relevant journal

- We provide round the clock customer support

- Convenient online submission

- Thorough peer review

- Inclusion in PubMed and all major indexing services

- Maximum visibility for your research

Submit your manuscript at www.biomedcentral.com/submit
() Biomed Central 